\title{
Management of Health Information in Malawi: Role of Technology
}

\author{
Patrick Albert Chikumba* \\ PhD Student, Department of Informatics, University of Oslo, 0316, Oslo, Norway \\ Applied Sciences Faculty, Department of Computing and Information Technology, University of Malawi, Malawi
}

\begin{tabular}{l} 
A R T I C L E I N F O \\
\hline Article history: \\
Received: 17 December, 2016 \\
Accepted: 20 January, 2017 \\
Online: 28 January, 2017 \\
\hline Keywords: \\
DHIS2 \\
Health information \\
Health information management \\
Health management \\
Health management information \\
system
\end{tabular}

\section{Introduction}

This paper is an extended version of the conference paper presented at IST Africa Week Conference 2016 [1]; excluding the case of Burkina Faso. This paper discusses in detail the existing technology gaps using DHIS2 (District Health Information System 2.0) as an example, and how Geographic Information System (GIS) and mobile application, as specific examples of technologies, can enhance health management information system (HMIS) in Malawi. HMIS is an information system for health

\footnotetext{
${ }^{*}$ Corresponding Author: Patrick Albert Chikumba, Department of Informatics,

University of Oslo, 0316 , Oslo, Norway

Phone: $+265885123533,+4795754367$

Email:pchikumba@poly.ac.mw,patricc@ifi.uio.no

www.astesj.com

https://dx.doi.org/10.25046/aj020118
}

\begin{abstract}
A B S T R A C T
This paper is an extended version of the conference paper presented at IST Africa Week Conference 2016 and it discusses in detail the existing technology gaps using DHIS2 (District Health Information System 2.0) as an example, and how Geographic Information System (GIS) and mobile application, as specific examples of technology, can enhance health management information system (HMIS) in Malawi. The paper focuses on management of health information. When organisation information is made available, it is expected that the decision-makers use it objectively making rational decisions. This can be technology. Along with the increase in strengthening HMIS, questions of how to support the management of information at various organizational levels arise. Research on technologies in health management in developing countries has been on single technologies. Therefore, in this paper, the interest is on multiple technologies and how they support each other to enhance health information management. It has been observed that when it comes to health information management, HMIS employs a mix of paper-based and technology-based practices. Taking into account the infrastructure in Malawi, as in many developing countries, this is probably the most feasible approach. Hence, discussions of existing technology gaps include both paper-based and technology-based practices and how to better support health information management practices through this mixed use of media. The case study confirms that technology plays a role in strengthening HMIS. However, this should be supported by enhancing a culture of information management. It has been noted that DHIS2 is the main information system but it requires the enhancement through inclusions of other technologies. The DHIS2 alone cannot do everything.
\end{abstract}

management at district, state, regional, and national levels [2]. Malawi HMIS supports community, facility, district, zonal and national levels. When we talk of HMIS in Malawi, DHIS2, as the central data repository, is the main focus. Hence, in this paper, discussions are around DHIS2. DHIS2 (www.dhis2.org) is a tool for collection, validation, analysis, and presentation of aggregate and patient-based statistical data, tailored (but not limited) to integrated health information management activities.

The availability of operational, effective and efficient HMIS is an essential component of the health management capacity [3] because it aims to ensure the appropriate and effective use of resources [4]. In Malawi, since 2002, there have been various 


\section{P. A. Chikumba / Advances in Science, Technology and Engineering Systems Journal Vol. 2, No. 1, 157-166 (2017)}

initiatives in order to strengthen its national HMIS; different technologies have been implemented including DHIS2.

Demand for health information exists [4]. Health managers always need health information when they are carrying out their activities. The health managers need necessary and sufficient information for monitoring, evaluating, and planning their activities [5]. In developing countries, it is important to strengthen health management teams by providing them with resources [6] such as information. When information is made available, it is expected that the decision-makers (e.g. in this study, health managers) use it objectively making rational decisions [3]. This can be achieved by how the information is organized, integrated and presented probably through technology.

Along with the increase in strengthening HMIS in Malawi, as in other developing countries, questions of how to support the management of information at various organizational levels arise. Research has been done on technologies in health management in developing countries. However, the focus has been on single technologies; for instance, recently in Malawi, there has been research on mobile health $[7,8]$, league table [9], GIS [10, 11], among others. In this paper, the interest is on multiple technologies and how they support each other to enhance health information management. From this perspective, two research questions have been drawn: How do technologies support each other in enhancing the management of health information? How can a new technology be integrated with existing ones in order to strengthen health management information systems? To answer these questions, the empirical data has been analysed and discussed from the perspectives of information cycle [12] and lines of development in health information systems (HIS) [13]. These perspectives are explained in the next section.

\section{Related Literature}

Health management is broad and includes, for example: care of health facilities, provision and handling of resources, coordination of health programmes, and reporting on health of communities and performance of health teams. According to Mintzberg framework, managerial roles are categorized as interpersonal, informational and decisional roles, which are further re-grouped in Shapiro framework as information generation and transmission, and formulation and execution of decisions [14]. In this paper, the focus is on the informational role, in which a manager is the monitor, disseminator, and spokesperson [14]. In order to play all these informational roles, health managers require managing properly information at their disposal, which include data collection, analysis, interpretation, utilization and dissemination of such information.

The important role of information in managerial work has been always recognized [15]. Information is a precondition for action [16] and it is gathered and used because it helps make a choice [17]. For instance, an organisation can use information to make sense of change in its environment; create new knowledge for innovation; and make decisions about courses in action. It is important for the information to have value in order to be useful. Information needs be in formats to support multiple users; otherwise it is of little value. The value of information depends in a well-defined way on the information's relevance to the decision to be made [17]. Schulte et al. [16] argue that the value is added to information when being transferred and distributed, for example, by translating from technical to general language, repackaging or organizing.
Hence, dissemination and communication are essential attributes of a health information system (HIS). HIS is any system that captures, stores, manages or transmits information related to the health of individuals or the activities of organisations that work within the health sector. As Almunawar and Anshari [18] point out, HIS is the interaction between people, process and technology to support the provision of essential information aiming at improving the quality of health care services. Health managers can use multiple kinds of information in combination and select information to suit their purposes. In this context, the technology plays a role in the sense that an organisation needs to use effective tools to generate and disseminate the required information. It has been observed that there are significant improvements in healthcare due to information and communication technologies [14]. Even in India, it has been observed that the computerization has led towards implementation of a good information system for service delivery, planning, monitoring, and supervision [19].

To achieve what have been discussed above, in summary, it is necessary to consider [20-22] (a) free information flow which is enabled by provision of technological infrastructure and organizational culture that secures support, enthusiasm and cooperation of staff and management; (b) information to be sent in a way that is useful to others without compromising confidentiality and packaged for all partners with considerable integration across organizational barriers; (c) working cooperatively and sharing information within and outside; and (d) information channels that guide workers to the pertinent data.

These issues concerning the management of information, particularly in health management, can be understood by considering theories presented by Braa and Sahay [12]. They point out that active and engaged management of information at all levels are key objectives for all efforts to strengthen HIS by considering inter-connected practices concerning analysis, interpretation, presentation and dissemination of information. Information management practices should be strengthened along various dimensions of the entire information cycle [12]. The information cycle is a set of stages of collection, collation and storage, processing, analysis, presentation, interpretation, dissemination and use of information. National HMIS in developing countries, like in Malawi, follow these stages; and at different stages, different technologies are used.

Research on the application of ICT in HIS is pursued in various areas including health management [23]. HIS can be composed of automated and non-automated agents, including computers and humans, for managing health information. To generate such information, the relevance of systematically processing data, information and knowledge is recognized [13]. A good HIS should provide access to its users on reliable, authoritative, useable, understandable, and comparative data.

Although HIS has evolved through several different technologies [18], primarily, it is not about technology; technologies are to support processes. Since 2002, in Malawi HMIS, various technologies have been introduced with the aim of strengthening the national HMIS, which has been also happening in other developing countries such as Tanzania [5], India [19], Pakistan [24], and Nigeria [2]. Therefore, in order to understand the nature of these technologies in HMIS (particularly DHIS2, GIS and mobile), with reference to what has been discussed above, different lines (or trends) of development in HIS from Haux [13] have been applied, which are briefly described below: 


\section{P. A. Chikumba / Advances in Science, Technology and Engineering Systems Journal Vol. 2, No. 1, 157-166 (2017)}

1. Towards computer-based information processing tools moving from paper-based processing and storage to computerbased processing and storage; although the adopting of technologies in HIS is increasing, paper-based is still favoured due to ease of use and legal reasons, among others.

2. From local to global information system architectures initially small and functionally limited applications have been developed for specialized departments or functions, but now development is focusing on national, regional or global systems.

3. From health care professionals to patients and consumers - at the beginning, computerised HIS were primarily intended to support health care professionals and administrative staff in hospitals; now it is recognized that HIS have to directly support all people with health questions and problems.

4. From using data only for patient care to research - until the last decade, there was an almost exclusive use of HIS data for patient care and administrative purposes, with some use for quality management and controlling; now there is an ability to extend the possibility of using data, primarily for patient care, health care planning and, above all, for clinical research.

5. From technical to strategic information management priorities - in computerised information systems, the main focus has been shifted from technical problems to organizational problems, social issues and change management aspects and as a result, the strategic long-term information management is regarded as a serious and necessary task.

6. Inclusion of new types of data - with a higher degree of use of computer-supported information processing tools, not only the functionality of HIS is extended, the types of data to be considered continuously increased.

7. Inclusion of new technologies - there has been the increase of functionality in computer-supported HIS with new extensions, e.g. enabling technologies for health monitoring, GPS-related technologies, and mobile-based applications.

In this paper, the assumption is that developments in HIS are related to technology improvements which can be well understood by considering stages in the information cycle; determining at which organizational levels and activities, expected technology can be introduced and support respectively. The author takes the perspectives of information cycle and lines of development in HIS as frameworks which can help him to understand various roles that technology can play in the health information management practices.

\section{Research Context}

This case study was conducted in Malawi health sector in 2015 at both national and district levels. Malawi is a landlocked country in southeast Africa and it borders with Tanzania to the northeast, Zambia to the northwest, and Mozambique to the east, south and west. The government is the main provider of health care in Malawi through Ministry of Health $(\mathrm{MoH})$. About $80 \%$ of population lives in rural areas and the population is affected by various diseases such as malaria, tuberculosis (TB), HIV/AIDS and nutrition-related diseases.

Malawi HMIS was introduced in 2002 as part of its health reforms in order to house all health data for decision making. It recognizes the evidence-based decision making which has been demonstrated by revising its national HIS policy with the main principle of "information for action, action for improving efficiency, quality, and equitable coverage". The primary objective is to provide up-to-date information for policy makers, planners, researchers and health programme managers that would allow guidance in the development, monitoring and evaluation of health. This HMIS has five levels: community, facility, district, zone and nation, which reflects the national organization of the health system. The health zone is a catchment area consisting of health districts within an administrative region. The health district is divided further into smaller catchment areas (i.e. health facility catchment areas) within which there are communities being composed of villages.

$\mathrm{MoH}$ is working with various stakeholders, both local and international, in setting-up and supporting various electronic health information systems (eHIS). These initiatives aim at strengthening the health systems by enhancing its capacity to use information for local action in supporting evidence-based decision making. They are also supported by various strategies and policies which emphasize the utilization of ICT in health sector with the aim of improving access and use of information. For instance, eHealth Strategy focuses on some areas of improving access to health services; improving healthcare; and strengthening monitoring and evaluation. It is expected that these issues can be implemented and managed by using sustainable national priority ehealth solutions that provide easy access to needed information in order to improve efficiency and effectiveness of health delivery services. National HIS strategy emphasizes the adoption and promotion of ICT use in the health sector. Even national ICT policy highlights the importance of integrating ICT in the health delivery system at all levels in order to improve management of information dissemination, among others.

In Malawi, there are various health programmes and in this study, malaria, nutrition, and family planning have been chosen as cases. Malaria is a major public health and economic problem in Malawi. Young children and pregnant women are the most at-risk population for malaria-related morbidity and mortality. Undernutrition particularly in women and children affects public health and development in Malawi; for example, the children suffer from chronic undernutrition (stunting) and micronutrient deficiencies. Malawi has made tremendous progress to increase contraceptive use and reduce fertility; and family planning services are provided in the health facilities. In addition, Central Monitoring and Evaluation Division (CMED) has also been chosen as a fourth case. To strengthen HMIS, MoH established CMED which is responsible for, among others, managing data and supporting technologies.

\section{Research Methodology}

This is the case study research in which qualitative interpretive methods were adopted with the aim of understanding social and natural settings of health managers, health coordinators, and HMIS officers (i.e. data managers) and particularly their health information management practices. The case study is an empirical inquiry that investigates a contemporary phenomenon within its real life context and multiple choices of evidence are used [25, 26]. The qualitative research helped the author to understand different ways of how health managers, health coordinators, and HMIS officers look at reality [27] and also to produce factual descriptions based on face-to-face knowledge of these participants in their every-day settings [28]. The aim of interpretive methods of research in information system (IS) is to produce an understanding 


\section{P. A. Chikumba / Advances in Science, Technology and Engineering Systems Journal Vol. 2, No. 1, 157-166 (2017)}

of the context of IS, and the process whereby IS influences and is influenced by the context [29].

Purposive sampling was used to select Blantyre health district, health programmes (malaria, nutrition, and family planning) and CMED, in which the sample was selected based on a particular characteristic [30]; i.e. the basis of researcher's own knowledge of population, its elements, and the nature of research aims [31]. Blantyre health district was chosen because it is one of the largest districts with the population of slightly over 1 million and it has both city (having a central/referral hospital) and rural settings. In addition, it was close to where the author lived; as a result it was relatively cheap to visit in terms of logistics. CMED was chosen because it is only the division within $\mathrm{MoH}$ which is responsible for managing data, implementing systems and providing technical support at all levels. All three chosen health programmes involve both children and women who are the most at-risk population as far as diseases are concerned in Malawi and they are fully implemented in DHIS2.

In this case study, data was collected through interviews as the main method and supplemented with document analysis and participant observation. At national level, semi-structured interviews were conducted with one statistician from CMED and one member of DHIS2 team while at district level, two HMIS officers (one from the central hospital and another from District Health Office) and three health programme coordinators (of chosen health programmes) were interviewed. The in-depth interview allowed the author to delve deeply into social and personal matters [32] and to ask follow-up questions and use nonverbal communication to his advantage [33,34]. Data collected through these interviews include information flow from community level to national level, challenges being faced, sources of information, presentation of information, technical support provision, technologies and information systems being used, data capturing and processing, and information availability.

Document analysis involved written data sources such as meeting minutes, reports, policies, strategies, manuals, job descriptions, and forms. The main objectives were to (a) understand policies, procedures and strategies that govern the participants in their work in respect to management of health information; (b) understand various roles of the participants; and (c) understand various ways of presenting data and information. Participant observations were done at the national level in order to understand institutional contexts in which the participants work. The author was part of DHIS2 team; implementing GIS. This method allowed the author to interact with participants and become part of their community [33] aiming at gaining an understanding of physical, social, and cultural contexts in which the participants live. This permitted the author evaluating whether there are unintended and unanticipated consequences which need to be addressed and whether there are areas of experience not touched by practice to which attention should be given.

This case study employed thematic analysis approach which is a qualitative analytic method for identifying, analysing and reporting patterns (themes) within data [35]. Data was analysed by classifying according to the major themes that were defined in the conceptual model which was derived from information cycle [12] and the lines of development in HIS [13].

\section{Health Information Management Practices}

As earlier mentioned, the health system in Malawi consists of five administrative levels: nation, zone, district, health facility and community. In this section, health information management practices are presented per these administrative levels. Data is collected and aggregated at facility level, and then integrated and analysed at district level. As in developing countries, e.g. Tanzania HMIS [5], the district is identified as a focal geographic unit in Malawi for integrating multiple health programmes and their information systems. The integration and analysis are done through the computerized system (DHIS2). Officers at zone and national levels rely heavily on districts in terms of data availability. It has been noted that majority of health programmes follow this hierarchy systematically from one level to another (e.g. malaria, nutrition, and family planning). Figure 1 shows the administrative levels and what happens at each level including technologies being used. All health programmes are supported at all levels by CMED which is the custodian of data and technologies.

In Malawi, there are health programmes with well-established data flows from the community up to national level. Each health programme has a manager at the national level and a coordinator at district level. At the health facility level, the responsibility is given to the health facility in-charge (or manager) as a focal person. CMED, as a HIS unit, has its own structure and wellestablished data flow. It has officers at all levels except at the community level.

The Ministry of Health $(\mathrm{MoH})$ established CMED in the Planning Department as one way of strengthening its HMIS. The overall objective of CMED is to continuously collect, analyse and use data to monitor and evaluate progress towards achieving goals and objectives of the health sector including the national development agenda. CMED involves in coordination, data management, advocate and facilitation of the information use in various activities such as policy formulation, planning and program implementation at all levels.

\subsection{Facility and Community Levels}

Every health facility (e.g. hospitals and health centres) has communities that it serves. At the community level, there are village and outreach clinics that are managed by community health workers (CHWs) who are referred as health surveillance assistants (HSAs) in Malawi. CHWs collect data using paper forms and send them to their respective health facilities. Similarly, at the facility level, health programmes have individual registers in which patient level data is recorded. Key players at health facilities are facility managers (mainly clinical officers or nurses) and CHWs. The health facility managers, as focal persons for health programmes, are responsible for compiling and reporting data to the district level with the support from CHWs. Some health facilities have statistical/data clerks, who aggregate, compile and report data on behalf of focal persons.

In each health programme, paper forms are used to report aggregate program level data to the respective district health programme coordinator. For monitoring and evaluation, there is another paper form (referred as HMIS form) which is used to record summary data from various health programmes at the health facility. This HMIS form is sent to respective HMIS officers at the district level. Apart from data recording, compilation and reporting, it is expected at the facility level to have some kind of data analysis and use for local actions. Participant $R$ commented: "Some health facility managers call for stakeholder meetings in their respective catchment areas to discuss health issues in these meetings collected data is used as evidence ..." Since there are no computerised information systems at health facilities, data is prepared manually. 


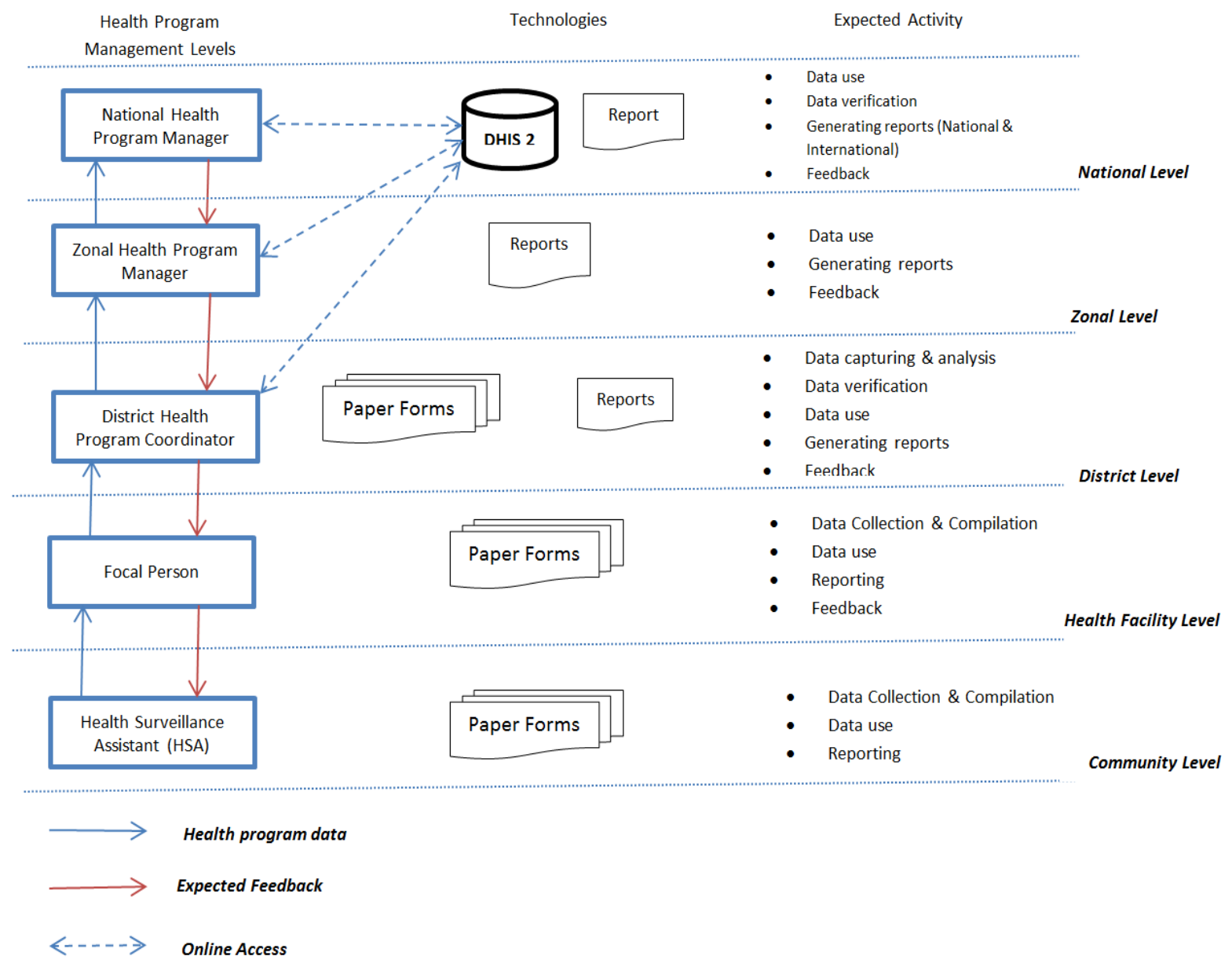

For central hospitals, as referral hospitals, data is collected from wards (taken as the 'community level') using paper forms and then sent to departments (taken as the 'health facility level'). In each department, there is a focal person who is responsible for compiling and reporting aggregate departmental level data to the HMIS officer at the central hospital. At the departmental level, it is also expected to analyse and use data for local actions and this analysis can be done using DHIS2 and other software such as spreadsheets and word processors. Participant $S$ said: "At a central hospital, technology for information processing and management is mainly at the departmental level where health personnel use computers to prepare reports."

\subsection{District Level}

Health programme coordinators receive aggregate program level data from health facilities and then verify the data before being captured into DHIS2 with the support from HMIS officer and data clerks. Similarly, HMIS officers get HMIS forms from the same health facilities; verify them and capture the data into DHIS2. At a central hospital, HMIS officer gets paper forms from department focal persons from which the summary data is compiled in HMIS forms and then captures the data into DHIS2. Specific health programme reports from central hospitals are sent directly to the respective health managers at the national level.
DHIS2 is used in data analysis, reporting, presentation, interpretation and even sharing. Since DHIS2 is the web-based system, it can be accessed at all levels by only registered users and who have the Internet access. At the district level, all health programme coordinators, HMIS officers and data clerks have access to DHIS2. However, it has been observed that HMIS officers have more access time than the health programme coordinators as Participant $T$ commented "... in most of the time I ask our HMIS officer to extract data for me from DHIS2 and even capturing into DHS2 ... I am always busy with coordination of my health programme activities and supervisory visits to health facilities ..." All three health programme coordinators extract data from DHIS2 by themselves or through the HMIS officer when preparing their reports. It is expected that HMIS officers produce district HMIS bulletins for their respective districts at least once a year and also send them to the zonal and national levels. Apart from DHIS2, some software tools, such as Excel, Word and PowerPoint, are also used.

\subsection{National Level}

At the national level, MoH through CMED is promoting the use of DHIS2 as a central data repository and some health programmes extract their data from DHIS2 provided the programmes and their data are available in DHIS2. HIS policy states that all programmes and partners with interest to collect 


\section{P. A. Chikumba / Advances in Science, Technology and Engineering Systems Journal Vol. 2, No. 1, 157-166 (2017)}

health data on basic health services shall utilize HMIS, and it further emphasizes that $\mathrm{MoH}$ shall establish separate national repositories for patient level data and aggregate data (currently DHIS2). However, in some cases, health programmes need data which is not available in DHIS2 and hence, they request it from other sources. Key players at the national level are health programme managers, economists and statisticians from CMED, and DHIS2 team, who all have access to DHIS2. MoH has inadequate technical capacity at the national level and as a result, majority of members of DHIS2 team are from development partners.

Although DHIS2 has a capability of data analysis and presentation, sometimes data is analyzed using other technologies, such as Excel, due to operational limitations of DHIS2 or required data is not available in DHIS2. For instance, Participant $U$ said: "DHIS2 cannot do everything ... we have some indicators that require spatial analysis and presentation ..."

\subsection{Extensions to DHIS2}

Since its introduction in 2012, there have been inclusions of technologies to support DHIS2. In this paper, two technologies have been identified: DHIS2 mobile and DHIS2 GIS which enhance HMIS at different stages. DHIS2 mobile was introduced in 2012 with the aim of improving timeliness of data collection and reporting. Paper-based system has resulted in many challenges including delays in reporting to districts. However, this mobile technology is only available in fifteen (15) out of twenty-nine (29) health districts, and also for few health programmes. DHIS2 mobile is a module within DHIS2 which allows data capture into DHIS2 through mobile phones at the data collection points (e.g. health facilities). Data is transferred from registers to paper forms and then captured into mobile application which transfers the data directly into DHIS2. Due to instability of the technology, paper forms are still used for backup purposes.

According to Moyo et al. [36], DHIS2 mobile has brought improvements to the timeliness of data reporting to districts although it has increased the workload of data clerks due to double reporting, i.e. same data is sent through mobile application and paper forms. They observed that for the successful use of DHIS2 mobile, some technical, organizational and behavioral issues need to be addressed; such as instability of, attitudes of users towards, and management support to the system, among others.

From 2015, MoH is introducing DHIS2 GIS in order to enhance data analysis, integration and presentation. It has been observed that many health programmes have recognized the power of GIS in data integration and visualization. From the interviews in this study, every participant, said "Yes" to GIS and below are some comments from the participants:

- Participant V: "Sometimes people come to my office asking for thematic maps particularly on distribution of facilities, catchment areas, road networks and disease surveillance which need GIS."

- Participant X: "GIS analysis should include utilization of health facility by its catchment area population."

- Participant Y: "We are interested using GIS to establish distances e.g. CHWs travel for resupply for their village clinics; mapping also activities covered by CHWs"

- Participant Z: "Our interest is to create maps of all established health services to conduct a gap analysis which will reveal the populations living in deprivation."
Demand for GIS in MoH was there as early as 2002 when a booklet of maps of the health facilities in each district across the country was produced and distributed in $\mathrm{CD}$. Since there have been various GIS initiatives such as purchasing of GPS in 2005, training HMIS officers from 2009, collecting coordinates of health facilities across the country in 2013, and mapping of village and outreach clinics in 2015-2016. In 2016, DHIS GIS was deployed with the expectation of being operational in 2017. DHIS GIS includes all health facilities down to village and outreach clinics; and all health programmes are to use the system.

\section{Existing Technology Gaps}

\subsection{Mix of paper-based and technology-based practices}

The case study has shown information management practices at different administrative levels (see Table 1). This section discusses some interesting points when it comes to technological support of information management. Malawi has put up national HMIS that covers the majority of the health sector. As shown in Table 1, when it comes to health information management, HMIS employs a mix of paper-based and technology-based practices. Taking into account the infrastructure in Malawi, as in many developing countries, this is probably the most feasible approach. Therefore, discussions of existing technology gaps include both paper-based and technology-based practices and how to better support health information management practices through this mixed use of media.

With reference to the information cycle [12], the case study shows that paper-based practices are mainly at community and facility levels while technology-based practices are at upper levels. The use of technology is rather concentrated around analysis, process and presentation of information. These activities are essential because they may add value to the information. Health managers need the information that makes sense and which knowledge can be generated from [37]. However, data collection and dissemination practices are also important that need to be enhanced through technology. Data collection is a fundamental attribute of every information system; without data HMIS is useless. Since transfer and distribution can add value to information as well [16], good dissemination and communication practices are essential. It has been observed that data collection is only supported to a very limited extent by technology, while dissemination processes are almost not supported by the technology. This can be due to both organisation- and technologyrelated factors. Sometimes, emails are used at individual level to distribute data or information; the email system is not institutionalized.

Data collection is done at community and facility levels in rural areas where access to technology is still limited and this is a wellknown and -documented obstacle in other studies. Some wellknown challenges are lack of electricity and little telecommunication coverage. It is difficult to extend DHIS2 to the facility level, since it requires the Internet connectivity and computers which are limited in health facilities. This forces health facilities to use paper forms for managing data. However, it has been noted that in some cases data is not reported to the district on time due to challenges brought by the use of paper forms, e.g. an increase in workload to health personnel, as also mentioned in Moyo et al. [36]. To ease workloads, $\mathrm{MoH}$ deployed statistical/data clerks to manage data and introduced DHIS2 mobile to some health facilities. 


\begin{tabular}{|c|c|c|}
\hline $\begin{array}{l}\text { Information } \\
\text { Cycle Steps }\end{array}$ & Administrative Level & Technology Used \\
\hline Collect & Community and facility levels & $\begin{array}{ll}\text { - } & \text { Paper forms in all } 29 \text { health districts } \\
\text { - } & \text { DHIS2 Mobile in only } 15 \text { health districts }\end{array}$ \\
\hline \multirow{2}{*}{$\begin{array}{l}\text { Collate and } \\
\text { store }\end{array}$} & Facility level & - $\quad$ Paper forms in all health districts \\
\hline & District level & - $\quad$ DHIS2 and paper forms for backup in all health districts \\
\hline \multirow{2}{*}{$\begin{array}{l}\text { Process and } \\
\text { analyse }\end{array}$} & Facility level & - Manually done at a small scale \\
\hline & District and national levels & $\begin{array}{ll}\text { - } & \text { Using DHIS2 at a large scale } \\
\text { - } & \text { Other software tools e.g. Excel, are used }\end{array}$ \\
\hline \multirow[t]{2}{*}{ Present } & Facility level & - Manually done at a small scale - paper-based \\
\hline & District and national levels & $\begin{array}{ll}\text { - } & \text { DHIS2 - text, graphs, tables (maps, yet to be used from 2017) } \\
\text { - } & \text { Other software tools e.g. Excel, are used }\end{array}$ \\
\hline Disseminate & All levels & $\begin{array}{ll}\text { - } & \text { Paper-based e.g. forms, bulletins, reports } \\
\text { - } & \text { DHIS2 - only for registered users } \\
\text { - } & \text { Emails and Internet }\end{array}$ \\
\hline \multirow[t]{2}{*}{ Use } & Facility level at a small scale & - Not available \\
\hline & District and national level at a large scale & - Not available \\
\hline
\end{tabular}

Although mobiles are used for reporting at health facilities in order to improve the information flow by enhancing the technological infrastructure [20-22], paper forms are still in use which results in increasing workload for statistical clerks. According to Moyo et al. [36], some challenges of using the DHIS2 mobile are technical while others are organizational in nature: for example, mobiles not functioning, poor screens for data entry, lack of management commitment, and even individual attitudes towards the technology. It seems these issues are contributing to a failure of scaling the technology to other health facilities and health programmes; as a result the whole project will probably fail; making health facilities to go back to the paper forms.

Malawi has adopted a system use practice that builds on quite few data managers (e.g. HMIS officers and DHIS2 team) who are key personnel in health information management practices. Although health programme coordinators and CMED officials, for example, have access to DHIS2 they usually depend on HMIS officers and DHIS2 team respectively to extract data from and even enter data into DHIS2. This can be due to lack of time, lack of access and even lack of skills [38]. It has been noted that HMIS officers and DHIS2 team have received more training and less attention have been given to health managers and coordinators who are actual information users.

On the other hand, HMIS officers and DHIS2 team can become a bottleneck and there is a risk that this might inhibit data management and use. Sometimes, HMIS officers are not physically available or busy with other issues which result in not providing assistance required. In this context, there is a possibility that the health programme coordinators use other sources of data apart from DHIS2. Although developing countries have implemented their respective national HMIS aiming to use its information, what should be understood is that health managers rely on both formal and informal sources of obtaining information to make rational decisions; in some cases they use information other than that is provided by formal organizational information systems [3]. This issue can be dealt with by providing more people in the health sector with access to the system, but it would furthermore require that this access is followed up by training. This can also promote a free information flow and practices of information sharing among information users [20-22].

However, some studies, such as that of Williamson and Kaasbøll [14], have argued that health managers depend much of the information from informal sources because, for example, formal health information systems are not comprehensive or readily available. This has also been evidenced in this case study in the way how DHIS2 is utilised. The case study points to an issue regarding the adaptation of DHIS2 and its appropriateness. Current DHIS2 in Malawi is mainly for data analysis, process, integration, presentation, and small extent of dissemination. CMED is promoting DHIS2 as the formal health information system. However, the main challenge is that no many health managers are using it due to various reasons.

For instance, DHIS2 can only be accessed by registered users, which leads to a limited dissemination of information. It means every time when unregistered user want data or information from 


\section{P. A. Chikumba / Advances in Science, Technology and Engineering Systems Journal Vol. 2, No. 1, 157-166 (2017)}

DHIS2 he/she needs to consult a registered user particularly HMIS officers and DHIS2 team. As observed in this case study (see Table 1), MoH depends much on paper-based system to distribute reports to information users which makes it difficult to access the information by all users. The dissemination can be improved by publishing health information on the Internet as pointed out in the HIS policy: "MoH shall maintain a web portal to make ready-touse data available to all stakeholders". Another issue is the availability of data in DHIS2. No all health programmes have data in DHIS2.

Although DHIS2 is the formal information systems for $\mathrm{MoH}$, some software tools such as Excel are used to large extent. This can be because Excel is commonly available and does not need an access to the Internet. It is a package which is easy to learn and use and having all necessary basic tools for simple data analysis. As mentioned in the previous section, the current DHIS2 has some limitations. In terms of analysis and integration, the DHIS2 is a good system. It requires enhancing its presentation and dissemination capabilities. For instance, $\mathrm{MoH}$ has recognized the power of maps in data presentation and visualization; as a result it is in a process of implementing GIS as part of DHIS2 (i.e. DHIS2 GIS). Presenting data in maps can provide more insight than a table of the same data [39] and be effective means for communicating messages clearly even to those who are not familiar with technology.

Table 2: Lines of Development in Malawi HMIS
Considering the characteristics of a good HMIS - such as free flow of information, presentation of information, cooperative working, and information channels - the case study points to the following findings. The free information flow in inhibited both by technological and organizational factors. Poor Internet and paper forms make it hard for information to flow, while availability of data managers creates a bottleneck for the information flow. This is also true for the creation of channels to the pertinent data. Data managers hold the expertise on this, but if they are not available the channel is blocked. Presentation and packaging of information is taken well care of by the data managers, but could be further enhanced by the technology in terms of dissemination.

\subsection{Role of DHIS2}

With reference to theories of Haux [13] of different lines of development in HIS, the study has shown that DHIS2 plays various roles in Malawi HMIS. For instance, DHIS2 is the information processing tool; provides national information system architectures; supports strategic information management; among others. For more details see Table 2. As observed in this study, DHIS2 cannot do everything. Hence, it needs to link or integrate with other systems. Therefore, further discussions are on how to manage this integration.

\begin{tabular}{|c|c|}
\hline \begin{tabular}{|l|} 
Line of Development \\
\end{tabular} & Status in Malawi HMIS \\
\hline $\begin{array}{l}\text { Towards computer-based } \\
\text { information processing tools }\end{array}$ & $\begin{array}{l}\text { DHIS2 was implemented with the aim of moving from paper-based to computer-based analysis, } \\
\text { processing, storage, and presentation. Although DHIS2 is the main formal information system, some } \\
\text { activities are still done on paper. Even the introductions of DHIS2 GIS and DHIS2 Mobile have the } \\
\text { purpose of enhancing processing and reporting respectively. }\end{array}$ \\
\hline \begin{tabular}{|l} 
From local to global \\
information system \\
architectures
\end{tabular} & $\begin{array}{l}\text { The introduction of DHIS2 has helped to move towards the national health information system through } \\
\text { which different health programmes are being integrated. CMED is working tirelessly on the } \\
\text { implementation of integrated national health information system. Although some health programmes } \\
\text { have individual applications, DHIS2 plays the role of data integration of such applications. However, } \\
\text { the main issue is interoperability between DHIS2 and other systems which requires much research and } \\
\text { development on how best it can be handled. }\end{array}$ \\
\hline $\begin{array}{l}\text { From health care } \\
\text { professionals to patients and } \\
\text { consumers }\end{array}$ & $\begin{array}{l}\text { DHIS2 has not yet reach a level of supporting patients and consumers. Originally, DHIS2 has been } \\
\text { designed for aggregate data for health administrators and managers. }\end{array}$ \\
\hline $\begin{array}{l}\text { From using data only for } \\
\text { patient care to research }\end{array}$ & $\begin{array}{l}\text { DHIS2 has enhanced the availability and accessibility of data. It has been observed that, to some extent, } \\
\text { players in health management, such as health programme managers and coordinators, health M\&E } \\
\text { officers, and health statisticians, are now requesting data from DHIS2 for planning and controlling } \\
\text { activities. Even some people outside MoH come and ask for data which CMED get from DHIS2. }\end{array}$ \\
\hline $\begin{array}{l}\text { From technical to strategic } \\
\text { information management } \\
\text { priorities }\end{array}$ & $\begin{array}{l}\text { It has been observed that most of time of implementing DHIS2 is for data management. DHIS2 team } \\
\text { spends most its time on organizing data, customizing data entry forms and checking quality, among } \\
\text { others. For instance, the setting up of DHIS2 GIS took only two days while cleaning and uploading } \\
\text { spatial data (coordinates of all health facilities and districts) into DHIS2 GIS took almost eight months. }\end{array}$ \\
\hline $\begin{array}{l}\text { Inclusion of new types of } \\
\text { data }\end{array}$ & $\begin{array}{l}\text { When DHIS } 2 \text { was being introduced in 2012, few health programmes were included. Now, majority of } \\
\text { health programmes have been and more will be included in DHIS2. This leads towards the inclusion of } \\
\text { new types of data. }\end{array}$ \\
\hline $\begin{array}{l}\text { Inclusion of new } \\
\text { technologies }\end{array}$ & $\begin{array}{l}\text { Since the introduction of DHIS2 in 2012, there have been a lot of extensions such as DHIS2 GIS and } \\
\text { DHIS2 Mobile. In addition, CMED and development partners are in progress of integrating DHIS2 with } \\
\text { other health information systems in order to improve availability and accessibility of data. }\end{array}$ \\
\hline
\end{tabular}


The DHIS2 was introduced as a computer-based information processing tool with the aim of moving from paper-based processing and storage [13] at district and national levels; focusing on specific information processing capabilities. From the perspective of information cycle, DHIS2 supports, may be, just half of activities in HMIS. Paper-based processing and storage is still available at facility level and dissemination and communication practices are still supported by the paper-based systems. This translates to the existence of technology gaps that need to be filled by introducing new technologies to support DHIS2, such as GIS and mobile included in this paper.

Introduction of new technologies or information systems to enhance the DHIS2 needs good plans and management commitments. As illustrated in Figure 2, it is essential to define how a new technology will fit in the existing context (e.g. DHIS2 environment). For example, the implementation of GIS was completely within the architecture of DHIS2. It depends fully on existing components of DHIS2 in terms of database and user interfaces; GIS is inbuilt in DHIS2. While for the mobile system, one part is within DHIS2 and another part is supported by other systems e.g. national mobile networks. In some cases (not included in this study) DHIS2 can either feed or get data from other independent systems (illustrated as System A in Figure 2). In this context, interoperability issues are considered.

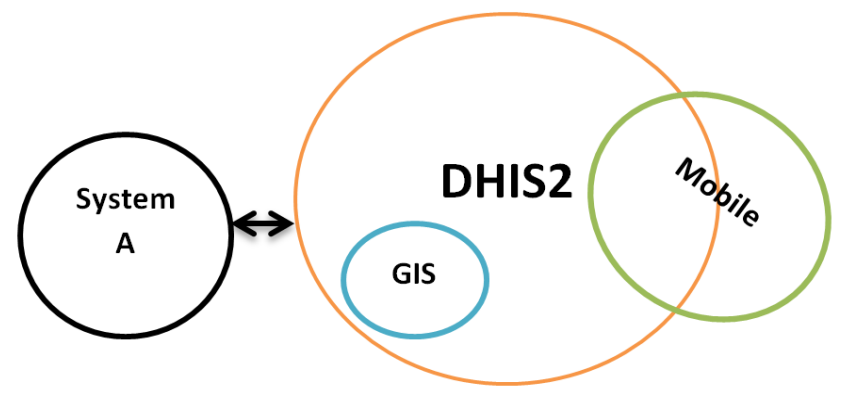

Figure 2: Ways of Linking DHIS2 to other systems/technologies

The author suggests the following when introducing a new technology in HMIS:

- identifying and prioritizing existing technology gaps that need much attention and this should be done with relation to activities in information cycle and administrative levels (e.g. DHIS2 mobile for data collection at the facility level and DHIS2 GIS for analysis and presentation at district and national levels);

- involving many health programmes that will benefit from the new technology and accommodating as much specific program needs as possible to increase a chance of acceptance;

- identifying interfaces for linking new technologies with the DHIS2 as a central system; and

- considering organizational factors including data issues (e.g. standards, sharing, etc.), people (roles, and required skills and knowledge), and procedures, policies and strategies, among others.

\section{Conclusion}

The case study confirms that technology plays various roles in strengthening HMIS. This has been also observed in some studies in developing countries such as Tanzania [5], India [19], Pakistan [24], and Nigeria [2]. For example, in India case, the computerization has enabled implementation of a good system in health care. In Nigeria case, the issue was strengthening HMIS through introduction of new technologies.

In recent years, in developing countries, there have been reforms in their health sectors by introducing HMIS and one component is to build formal information systems for providing necessary and sufficient information to facilitate evidence-based decision making and effective management of health at all levels of the organisation. In some developing countries (e.g. Malawi, Tanzania and Nigeria) DHIS2 has been implemented as their formal information systems for the health management. It seems that the technology needs to be supported by paper-based systems as observed in this case study and cases of Tanzania [5], India [19], Pakistan [24], and Nigeria [2]. Activities in some levels (particularly, lower levels) are supported by paper forms while other levels (e.g. upper levels) use computerised information systems. This means that HMIS cannot exclude paper-based systems.

Another observation is that when a new technology is being introduced, it is usually an extension to the formal information system (e.g. DHIS2). This case study has shown that the introduction of mobile application and GIS are the extensions to DHIS2. This has also happened in Nigeria where DHIS2 is the formal information system and mobile technology was introduced as an extension to DHIS2.

Therefore, to elaborate the mix of paper-based and technologybased practices, and extensions to the formal information systems using the case of Malawi, this case study focused on two: how different technologies support each other in enhancing the management of health information; and how a new technology can be integrated with existing formal information systems in order to strengthen health management information systems. From the analysis and discussions in this paper, it is concluded that in developing countries, we need both paper-based and technologybased systems for the health information management and these systems support each other. We should gradually move from the paper-based to technology-based environment by introducing new technologies as extensions to what we have as our formal information systems. Due to our infrastructural challenges, it is difficult to implement computerised information systems that can support all activities of information management and at all organizational levels.

However, due to well-known challenges of paper-based systems in developing, such as delay in reporting, it is obvious that technology-based systems will be affected regardless how good they are. For example, in Malawi [36] and Nigeria [2], mobile systems were introduced to minimize challenges of manual data collection, e.g. data timeliness and accuracy. The author suggests that further investigations should be taken to establish how best paper-based and technology-based systems can be interfaced in order to improve the efficiency.

As earlier pointed out, developments in HIS are not only on technologies, organizational, social, economic, political and 


\section{P. A. Chikumba / Advances in Science, Technology and Engineering Systems Journal Vol. 2, No. 1, 157-166 (2017)}

cultural issues should be considered. A culture of information management should be enhanced. It has been noted that in Malawi, DHIS2 is the main information system which leads towards moving from local to national information system architectures [13] in the sense that it is taken as a national platform for health programmes. It also addresses organizational problems rather than technical ones; e.g. integration of health programmes to improve data availability and accessibility.

\section{References}

[1] P. A. Chikumba, and S. L. Ramussen, "Management and use of health information in Malawi and Burkina Faso: the tole of technology" in ISTAfrica Week Conference 2016, Durban South Africa, 2016.

[2] I. Asangansi, "Understanding HMIS implementation in a developing country Ministry of Health context - an institutional logics perspective" Online Journal of Public Health Informatics, 4(3), 2012.

[3] R. I. Mutemwa, "HMIS and decision-making in Zambia: re-thinking information solutions for district health management in decentralized health systems" Oxford University Press in association with The London School of Hygiene and Tropical Medicine, 2005.

[4] A. Garrib, N. Stoops, A. McKenzie, L. Dlamini, T. Govender, J. Rohde, and K. Herbst, "An evaluation of the District Health Information System in rural South Africa" South African Medical Journal, 98(7), 549-552, 2008

[5] M. Smith, S. Madon, A. Anifalaje, M. Lazarro-Malecela, and E. Michael, "Integrated Health Information Systems in Tanzania: Experience and challenges" The Electronic Journal on Information Systems in Developing Countries, 33(1), 1-21, 2008.

[6] C. P. Conn, P. Jenkins, and S. O. Touray, "Strengthening health management: experience of district teams in The Gambia" Health Policy and Planning, 11(1), 64-71, 1996.

[7] T. D. Manda, and T. A. Sanner, "The mobile is part of a whole: implementing and evaluating mHealth from an Information Infrastructure perspective" International Journal of User-Driven Healthcare, 4(1), 1-16, 2014.

[8] M. S. Chawani, and C. Ngoma, "Use of mobile technology to support provision of cimmunity-based maternal and neonatal care in developing countries" in International Conference on Health Informatics, Rome Italy, 2011.

[9] C. Moyo, M. H. Frøyen, J. I. Sæbø, and J. J. Kaasbøll, "Using performance league tables to provide feedback in health information systems in Malawi" in ifip9.4 Conference, Negombo Sri Lanka, 265-276, 2015.

[10] B. Msiska, and P. Chikumba, "Challenges and opportunities in using GIS for monitoring and management of HIV/AIDS: A case study from Malawi" Malawi Journal of Applied Science and Innovation, 1(2), 27-36, 2015.

[11] P. A. Chikumba, "Application of Geographic Information System (GIS) in drug logistics management information system (LMIS) at district level in Malawi: opportunities and challenges" AFRICOMM 2009. LNICST, 105115: Springer, Heidelberg, 2010.

[12] J. Braa, and S. Sahay, Integrated Health Information architecture - power to the users: design, development and use, Sanjay Sethi for MATRIX Publishers, 2012.

[13] R. Haux, "Health information systems - past, present, future" International Journal of Medical Informatics, 75, 268—281, 2006.

[14] L. Williamson, and J. Kaasbøll, "Health information and managerial work: exploring the link" in International Conference on Social Implications of Computers in Developing Countries, Dubai UAE, 2009.

[15] C. W. Choo, "Environmental scanning: acquisition and use of information by Chief Executive Officers in the Canadian Telecommunications Industry" PhD Thesis, University of Toronto, 1993.

[16] P. A. Schulte, A. Okun, C. M. Stephenson, M. Colligan, H. Ahlers, C. Gjessing, G. Loos, R. W. Niemeier, and M. H. Sweeney, "Information dissemination and use: critical components in occupational safety and health" American Journal of Industrial Medicine, 44, 515-531, 2003.

[17] M. S. Feldman, and J. G. March, "Information in organization as signal and symbol" Administrative Science Quarterly, 26(2), 171-186, 1981.

[18] M. N. Almunawar, and M. Anshari, "Health Information Systems (HIS): concept and technology" in International Conference Informatics Development, Cornell, 2011.

[19] A. Krishnan, B. Nongkynrih, K. Yadav, S. Singh, and V. Gupta, "Evaluation of computerized health management information system for primary health care in rural India" BMC Health Services Research, 10(310), 2010.
[20] K. Bystrom, and K. Jarvelin, "Task complexity affects information seeking and use" Information Processing \& Management, 31(2), 191-213, 1995.

[21] A. Curry, and C. Moore, "Assessing information culture - an exploratory model" International Journal of Information Management, 23, 91-110, 2003.

[22] D. O. Case, "Information behavior," Annual Review of Information Science and Technology, 40(1), 293-327, 2006

[23] M. S. Chawani, "Development of electronic medical record systems for maternal health services in rural settings: An action research study from Malawi” PhD Thesis, University of Oslo, 2014.

[24] R. Kumar, B. T. Shaikh, A. K. Chandio, and J. Ahmed, "Role of Health Management Information System in disease reporting at a rural district of Sindh" Pakistan Journal of Public Health, 2(2), 10-12, 2012.

[25] C. Yen, M. Woolley, and K. Hsieh, "Action case research: a method for the accumulation of design theory/practice knowledge in practice" Working papers in Art \& Design, 01/2002, 2002.

[26] L. O. Johansson, B. Cronquist, and H. Kjellin, "Visualization as a tool in action case research" in 6th European Conference on Research Methodology for Business and Management Studies, UK, 2007.

[27] B. Hancock, E. Ockleford, and K. Windridge, An Introduction to Qualitative Research: The NIHR RDS EM/YH, 2007.

[28] G. J. Ebrahim, and K. R. Sullivan, Mother and Child Health - Research Methods, Book Aid, 1995.

[29] K. E. Berntsen, J. Sampson, and T. Østerlie, "Interpretive research methods in computer science" DIF8916 Method Essay, Norwegian University of Science and Technology, 2004.

[30] L. R. Frey, C. H. Botan, and G. L. Kreps, Investigating communication: an introduction to research methods, Allyn and Bacon, 2000.

[31] E. Babbie, Survey research methods, Wadsworth Publishing Company, 1990.

[32] B. DiCicco-Bloom, and B. F. Crabtree, "Making sense of qualitative research: The qualitative research interview" Medical Education, 40, 314321, 2006.

[33] D. L. Driscoll, "Introduction to primary research: observations, surveys, and interviews" Writing Spaces: Readings on Writing, 2, 2011.

[34] N. Mathers, N. Fox, and A. Hunn, "Trent Focus for research and development in primary health care: using interviews in a research project" Trent Focus, 1998.

[35] V. Braun, and V. Clarke, "Using thematic analysis in Psychology" Qualitative Research in Psychology, 3, 77-101, 2002.

[36] C. Moyo, T. Nkhonjera, and J. Kaasbøll, "Using mobile technology to improve timeliness of data reporting: A case study from Malawi" in ISTAfrica Conference Week 2015, Lilongwe Malawi, 2015.

[37] C. W. Choo, "The knowing organization: how organizations use information to construct meaning, create knowledge and make decisions" International Journal of Information Management, 16(5), 329-340, 1996.

[38] R. Bertulis, "Barriers to accessing evidence-based information" Nursing Standard, 22(36), 35-39, 2008.

[39] R. P. Fisher, and B. A. Myers, "Free and simple GIS as appropriate for health mapping in a low resource setting: a case study in eastern Indonesia" International Journal of Health Geographics 2011, 10(15), 2011. 